\title{
SETAC Europe young scientist LCA award 2021 for T. Schaubroeck
}

\author{
Joost Dewaele ${ }^{1}[$ \\ Received: 12 May 2021 / Accepted: 19 May 2021 / Published online: 28 May 2021 \\ (c) The Author(s), under exclusive licence to Springer-Verlag GmbH Germany, part of Springer Nature 2021
}

\begin{abstract}
At the 31st SETAC Europe annual meeting, virtual Scientific Conference 3-6 May 2021, T. Schaubroeck received the SETAC Europe Young Scientist LCA Award 2021.
\end{abstract}

The SETAC Europe LCA Steering Committee recognizes Thomas for his efforts in development and application of LCA. Thomas has showcased a wide set of skills in the broad scientific field of environmental sustainability assessment. Advancement and application of LCA are at the core of his research, which also covers improvements in life cycle impact assessment, life cycle sustainability assessment (LCSA), and life cycle inventory modeling and more.

Thomas has demonstrated being able to break with existing paradigms and generate novel ideas and concepts. One example is the idea to consider well-being as pivotal AoP (Area of Protection) and endpoint for LCSA. Whilst not everyone may agree, and the use of such concept is yet to prove itself in practice, the shear idea on using well-being, covering "happiness and health," as finality for sustainability is interesting at the very least.

Quite a bit of his work is taking place at the interphase of disciplines or taking a multidisciplinary approach. One example relates to using ecosystem service assessment in combination with LCA. At a time where assessment of ecosystem services is not yet fully integrated into LCA methods, Thomas has made a strong case arguing for better integrating of "damaging" ecosystem "dis"services, thus enabling an objective assessment. Another example of his research concerns improving/reinstating the use of LCSA methods to analyze the sustainability impact of circular economy systems.
We also note interesting effort in advancing inventory modeling in hybrid and consequential LCA, an area that is difficult and regarded as hindering scientific advancement by some. Thomas has been influential in highlighting the relevance of completing system boundaries and realistic modeling of the economy and has demonstrated the importance of temporal aspects in consequential LCA, leading to a framework that enables including that aspect.

Alongside his efforts to advance science and public dissemination of his work through journal publications, journal reviews, and scientific conferences, he has shown involvement in practical application of LCA in industry-related activities, such as LCA of wastewater treatment, flooring systems, and food/meals. Finally, Thomas has a passion for teaching and has been an active lecturer on LCA for 2 years, besides guiding master and $\mathrm{PhD}$ students to complete their LCA dissertations.

SETAC Europe Young Scientist LCA award is sponsored by Lenzing AG (https://www.lenzing.com) and Springer Verlag (http://www.springer.com).

Heinz Stichnothe (Chair)/Joost Dewaele (Award Manager). On behalf of the SETAC Europe LCA steering Committee.

Publisher's Note Springer Nature remains neutral with regard to jurisdictional claims in published maps and institutional affiliations.

Communicated by Matthias Finkbeiner.

Joost Dewaele

dewaele.j@pg.com

1 Procter \& Gamble, Strombeek-Bever, Belgium 